\title{
REFORMA DA POLÍCIA E FORMAÇÃO POLICIAL NO PROGRAMA DELEGACIA LEGAL
}

\author{
Hildebrando Ribeiro Saraiva ${ }^{1}$
}

RESUMO: Este artigo faz uma breve descrição do Programa Delegacia Legal, implementado na Polícia Civil do Rio de Janeiro, desde 1999. O projeto trouxe grandes modificações nas rotinas e na estrutura das delegacias policiais visando alterar a relação da polícia com a sociedade e incrementar a capacidade investigativa da Polícia Civil. Uma marca do programa foi o investimento na formação permanente dos policiais que passaram a frequentar cursos de atualização mensais. Discutimos que a resistência dos policiais aos cursos propostos vincula-se mais à inadequação do formato e do conteúdo das iniciativas pedagógicas que a uma postura antiteórica. Apesar das intenções reformadoras, os cursos acabam por reforçar uma perspectiva repressiva da atuação policial deixando de reforçar outras competências do mandato policial necessárias para a atuação policial no Estado democrático de direito.

PALAVRAS-CHAVE: Programa Delegacia Legal, formação policial, políticas públicas

Recebido em: outubro de 2012

Aceito em: março de 2013

Para citar este artigo:

SARAIVA, Hildebrando; Reforma da Polícia e formação policial no programa Delegacia Legal. In: Revista Intratextos, 2013, vol 4, no1, p. 53-72. DOI: 10.12957/intratextos.2013.8566

1 Hildebrando Saraiva é Cientista Social pela UFRJ e mestrando do PPCIS da UERJ. Email: hildebrandosaraiva@yahoo.com.br

INTRATEXTOS, Rio de Janeiro, Número Especial 4(1): 53-72, 2013. ISSN 2176-6789

Página 53 


\section{Introdução}

A análise de políticas públicas foi um tema tradicionalmente abordado pela ciência política com a pressuposição de que a interpretação do desenho institucional poderia oferecer uma chave de análise para compreender a estrutura do poder estatal e verificar a distribuição das forças políticas nos lugares de tomada de decisão. Importava, prioritariamente, o poder e as forças sociais que o ocupavam. Miranda (2007), entretanto, chama atenção para uma abordagem distinta, inspirada pela antropologia, onde o foco de nossas pesquisas estivesse voltado não apenas para esses lugares de poder mas também para as práticas dos sujeitos responsáveis pela implementação das formulações políticas definidas na cúpula.

Ao contrário dos cientistas políticos, que se preocupam com a análise das instituições políticas, no sentido da luta pelo controle das posições, o antropólogo tem buscado compreender como as instituições e/ou governos atingem seus propósitos públicos, o que tornou vitalmente importante a distinção entre as práticas de implementação das decisões políticas e as práticas da rotina administrativa. (MIRANDA et al. 2007, s/i)

Acreditamos que essa perspectiva metodológica auxilia a construção de uma compreensão mais qualificada das tensões sempre presentes na aplicação de políticas públicas e nos afasta de concepções inspiradas por estruturalismos de qualquer espécie. O estudo das instituições burocráticas não precisa, necessariamente, estar orientado por um formalismo institucional que busque identificar nos desenhos organizativos as razões para o sucesso ou o fracasso dos projetos políticos. Da mesma forma, essa nova orientação poderia nos ajudar a perceber que reengenharias institucionais, por mais radicais que sejam, continuam obrigadas a disputar sua significação e seu alcance com os hábitos e as representações dos atores envolvidos nessas transformações.

Não é raro, quase sempre após alguma tragédia, que os representantes das instituições policiais sejam cobrados sobre a formação de seus integrantes. Sempre que um ato violento da polícia aparece na agenda pública, o tema da formação policial ressurge como explicação para o equívoco dos policiais. A teoria que acompanha essa conclusão se fundamenta sobre a hipótese de que haveria um déficit no processo de formação policial e que a tarefa adequada para reverter esse estado de coisas seria aumentar e estender a instrução dos policiais sobre temas caros à cidadania e à ordem democrática. Nesse texto pretendemos verificar tal hipótese, além de expor 
impressões recolhidas de forma não sistemática da atividade profissional no interior de delegacias de polícia e da recepção das diretrizes do projeto de formação permanente do Programa Delegacia Legal.

A motivação para esse texto surgiu da minha experiência profissional, desde 2002, quando ingressei na Polícia Civil do Rio de Janeiro. Desde essa data acompanho - como "nativo" - a implementação e a expansão do Programa Delegacia Legal, uma vez que sempre fui lotado em delegacias pertencentes a tal programa, que apresentarei com mais detalhes na seção seguinte.

Meu pertencimento institucional oferece-me potencialidades e perigos: as primeiras advêm da possibilidade que tenho de frequentar e testemunhar ações, ambientes e mecanismos muitas vezes interditados a um entrevistador; os perigos são provenientes da tentação de supor que esse mesmo pertencimento me possibilitaria captar a realidade dos fenômenos sociais pela simples empiria. A autoridade da etnografia já foi questionada desde a obra clássica de Clifford (2002) e parte da experiência que acumulei no campo de pesquisa não foi orientada pela problematização necessária a uma observação participante, como definiria Malinowski. Neste sentido, as observações não sistemáticas por mim realizadas servem aqui de orientação para analisar a bibliografia sobre o tema. Posteriormente, trabalharei com os dados empíricos resultantes do meu trabalho de campo.

Durante o período que trabalho na polícia civil, estive lotado em 06 delegacias: duas localizadas na Baixada Fluminense, três delas na Zona Norte e outra na Zona Oeste. Apesar das diversidades, em todas essas delegacias encontrei resistência e críticas dos policiais aos cursos de formação permanente do Programa Delegacia Legal. Partimos da hipótese de que a resistência dos policiais aos cursos de formação, não representa uma atitude anti-teórica e sim um desencontro entre o que a Administração entende como aprimoramento policial e o que os policiais assim compreendem. Poderemos constatar que, apesar das intenções reformadoras, o caminho trilhado acaba por reforçar equívocos e consolidar a concepção repressiva da atividade policial. Por fim, tentaremos detectar estratégias capazes de superar a resistência dos policiais e elaborar uma concepção mais plural do mandato policial, exigência atualmente dirigida à polícia. 


\section{Reforma da polícia no programa delegacia legal}

Desde o ano de 1999, no Rio de Janeiro, a Polícia Civil desenvolve um projeto intitulado de Programa Delegacia Legal. Trata-se de uma iniciativa do governo estadual, que visa reestruturar radicalmente a organização e o funcionamento das delegacias policiais. Seu objetivo é alterar a relação entre polícia e cidadão, dando maior transparência às atividades policiais e buscando aumentar a confiança da população na polícia. ${ }^{2}$

A radicalidade da transformação começava pelos prédios das delegacias, que sofreram uma profunda reforma arquitetônica, sendo muitos demolidos para a construção de novos. A partir do Programa eles foram padronizados, dando maior conforto ao policial de plantão - com a instalação de aparelhos de ar condicionado, dormitórios e banheiros próprios - e tornando o espaço das delegacias um local mais funcional. Ao contrário das delegacias tradicionais, onde o atendimento e a investigação eram realizados a portas fechadas, nas delegacias legais os policiais trabalham em um grande salão, em mesas separadas por divisórias de vidro, deixando seus atos permanentemente sob controle e supervisão, contraditoriamente à lógica inquisitorial do sigilo e do segredo. As portarias de quase todas as Delegacias Legais são de vidro temperado e de seu exterior se percebe o que está acontecendo nesse salão. Conjuntamente, foram instalados bebedouros, telefones e banheiros públicos, caracterizando uma mudança qualitativa na compreensão de polícia e serviço público. O interior do prédio, antes "privado", passa a ser um espaço público: muitas pessoas passaram a entrar nas delegacias simplesmente para usar o banheiro, beber água, usar os telefones. Não se trata de uma questão menor: tais medidas de fato colaboram para a percepção da função pública da polícia e criam mecanismos contrários à lógica da polícia "blindada". Mecanismos nem sempre são eficazes, mas têm sua importância.

Desde a implementação do programa, a rotina de trabalho também foi profundamente alterada, deixando de existir a estrutura tradicional da delegacia - dividida em núcleos de investigação e cartório. Nas delegacias tradicionais há uma separação entre um setor que registra as ocorrências e outro que investiga, o que levaria àquele setor que registra, a uma relação superficial com seu ofício, compreendido não como fim, mas como atividade-meio e, ao setor que investiga, uma defasagem de alguns dias para o início de qualquer investigação da delegacia.

2 Roteiro guiado do Programa Delegacia Legal. Disponível em <www.delegacialegal.rj.gov.br> INTRATEXTOS, Rio de Janeiro, Número Especial 4(1): 53-72, 2013. ISSN 2176-6789 Página 56 
O trâmite dos procedimentos da delegacia convencional inicia-se por um policial que fica no balcão logo na entrada da delegacia para atender ao público que demandas as atividades policiais (...) esse policial estava responsável por atender às ocorrências policiais (principal função a ele destinada), por atender a maior parte dos telefonemas que são dirigidos à delegacia ou a alguém que esteja necessitando de uma informação, e por dirigir essas pessoas aos setores que deveriam procurar na delegacia, caso fosse necessário. A chave da carceragem da delegacia também ficava com esse policial do atendimento, de forma que eram inúmeras as funções que ele acumulava. (PAES, 2006, p.61)

Pelo projeto do Programa Delegacia Legal (PDL), os policiais que fazem os registros são os responsáveis pelo andamento das investigações posteriores; no lugar desse policial que atendia sozinho todos os registros do plantão, e depois os transferia para os grupos "especializados" de investigação ${ }^{3}$, foi criado um grupo de policiais (GI - Grupo de Investigação) cuja atribuição primordial é o atendimento ao público: a confecção de Registros de Ocorrência e o andamento das investigações. Acreditava-se que essa alteração pudesse provocar um maior envolvimento do policial responsável pelo registro do fato, acelerar o início da investigação, além de possibilitar a identificação de responsabilidades nos inquéritos e procedimentos. Para isso, toda a carga de inquéritos anterior a data do ingresso da unidade policial no PDL era transferida para delegacias de acervo cartorário (DEAC) que ficaram responsáveis pela condução dos inquéritos antigos até sua conclusão. Assim, os policiais da nova Delegacia Legal começavam sem nenhum inquérito sob sua responsabilidade o que pode nos ajudar a verificar, após uma década, onde a reforma conseguiu alcançar alterações e resultados distintos do modelo tradicional.

Com o advento do novo modelo, foram extintas também as carceragens no interior das delegacias. O programa previa a construção de Casas de Custódia para receber os presos daí oriundos, eles foram "remanejados" para onze casas de custódia. Com isso, um efetivo de policiais foi liberado da função de carcereiros, passando a exercer tarefas próprias da função policial dentro das delegacias, como o atendimento ao público na confecção de Registros de Ocorrência ou na investigação de inquéritos. (Roteiro guiado/ PDL)

O balcão de atendimento - responsável pelo primeiro atendimento ao cidadão que entra em uma delegacia - é composto por profissionais e estagiários da área de humanas, como psicologia e serviço social. É interessante notar o fato de que o PDL veta estudantes de Direito, numa tentativa de evitar que os integrantes do balcão de atendimento façam qualquer orientação

3 Nas delegacias tradicionais, existiam três núcleos de investigação: Homicídios, Roubos e Furtos e, por último, Entorpecentes.

INTRATEXTOS, Rio de Janeiro, Número Especial 4(1): 53-72, 2013. ISSN 2176-6789

Página 57 
jurídica. Sua atividade, portanto, não era impedir que o cidadão acessasse o policial, era apenas organizar esse acesso. Sua função seria fazer uma recepção e humanizar o atendimento policial quando as pessoas vitimizadas chegam nervosas ou descontroladas; e liberar os policiais para as "tarefas específicas de policial", segundo o Programa. Ainda no mesmo sentido, para reduzir o envolvimento dos policiais em atividades de natureza administrativa foi criada a função de 'síndico de delegacia': um técnico não policial para cuidar da manutenção predial, do estoque de materiais e do funcionamento de equipamentos.

Parece ficar clara a intenção do projeto de reforma na polícia civil. O trabalho policial deveria concentrar-se nas tarefas ditas essenciais e próprias de sua competência: a investigação criminal. A hipótese parecia ser de que liberando os policiais de tarefas não essenciais sobraria mais tempo para se dedicarem à prática investigativa, ou como prefere o Direito, à apuração de autoria e materialidade. Uma reforma estrutural - as instalações da delegacia, seu funcionamento e suas rotinas - seria capaz de levar a uma reforma moral - a adoção de novas práticas, o engajamento com o seu ofício e a busca por uma outra relação com a população.

Contudo, essas não foram as únicas mudanças. Entre tantas inovações implementadas está a capacitação permanente dos policiais civis. A questão da formação policial é um ponto muito importante: pensar formação policial é, inevitavelmente, pensar também o que é a polícia, quais são suas práticas adequadas e seus limites. O que é uma polícia competente, ou incompetente, define instruções importantes na orientação da ação pedagógica na polícia. A falta de uma política pública de formação policial é um grave equívoco que leva a uma postura reativa nessa área das instituições policiais.

Antes do Programa Delegacia Legal, as iniciativas de formação ou aperfeiçoamento eram esparsas e desconexas e quase sempre respondiam a uma demanda externa e pontual. A partir do seu início, verificou-se um esforço na tentativa de dar organicidade ao processo de formação continuada dos policiais. Todos os policiais lotados em delegacias pertencentes ao PDL recebiam uma gratificação de $\mathrm{R} \$ 500,00$ para participarem de um curso de atualização mensal. Com esta gratificação, o governo do Estado parecia dar clara ênfase na formação continuada como estratégia para se alcançar alterações e práticas mais adequadas. 
O curso de aperfeiçoamento já experimentou diferentes formatos. No início do Programa, esses cursos eram ministrados em aulas presenciais na Academia de Polícia. No entanto, por se tratar de uma instituição estadual, muitos policiais criticavam a necessidade de se deslocar de municípios distantes para as aulas no Centro do Rio de Janeiro. Logo após tentou-se implementar os cursos nas próprias delegacias, mas nos dias de folga, o que causava o mesmo problema: policiais que moravam distante dos seus locais de trabalho também protestavam pela obrigatoriedade de se deslocar muitos quilômetros para frequentar as aulas e assim ter direito à bolsa-formação. Por último, foi possível ministrar os cursos via web, formato que se mantém desde 2002 até a atualidade.

\section{Críticas e resistências ao novo modelo de formação}

As mudanças, naturalmente, causam desconforto. As resistências daí advindas podem ser interpretadas não apenas negativamente - como uma incompatibilidade do novo - mas também positivamente, como uma reação às novas demandas e à efetividade das mudanças. Muitos policiais criticavam o modelo do curso de aperfeiçoamento e, ainda hoje, é frequente presenciar relatos dos policiais reclamando do conteúdo do curso que eles qualificam como exageradamente teórico e distante de seus problemas do dia-a-dia. A velha argumentação da separação entre teoria e prática é cotidianamente reforçada no imaginário dos policiais que não enxergam nos cursos oferecidos uma utilidade para seu trabalho cotidiano. No entanto, cabe investigar se tal resistência se deve a alguma "subcultura" policial.

Entre muitas questões, duas podem ter impulsionado essa resistência: no início da implementação do PDL, pelo fato de coexistirem dois modelos de delegacia - a Legal e a tradicional - a bolsa-formação passou a ser identificada com a Delegacia Legal e não com o curso de aperfeiçoamento. Em outras palavras, policiais que cumpriam as mesmas tarefas em delegacias diferentes, recebiam $\mathrm{R} \$ 500,00$ a mais em seus contra-cheques por estarem lotados em unidades que pertenciam à Delegacia Legal. Além disso, não era possível estar lotado em uma delegacia fora do projeto e receber a bolsa-formação, mesmo para quem estivesse disposto a participar dos cursos de qualificação. Muitos policiais passaram a buscar a lotação em uma Delegacia Legal visando um aumento salarial. Com isso os cursos acabaram sendo percebidos 
como uma espécie de mecanismo capaz de retirar a "gratificação" da Delegacia Legal: quem não frequentasse os cursos, ou não obtivesse nota mínima, tinha sua bolsa cortada. É interessante notar que no linguajar dos policiais a bolsa-formação foi rebatizada de "gratificação da Legal". Esse vínculo entre a formação continuada dos policiais e o incentivo monetário foi completamente alterado: os $\mathrm{R} \$ 500,00$ passaram a ser chamados pelos policiais de "quinhentos da Legal" e os cursos de formação foram apelidados de "cursinho dos quinhentos"

O pessoal que trabalha na [nome da unidade] questiona muito, porque aqueles que trabalham em Delegacia Legal têm uma gratificação. Mas por que essa diferença é tão grande? É R $\$ 500,00$, isso é muita coisa! Que é para fazer aqueles cursos que o pessoal faz? Mas todo mundo aqui tem aquele curso. A maioria tem curso da Delegacia Legal aqui, só que não recebe os $\mathrm{R} \$ 500,00$. Não se aprende nada! A Delegacia Legal não me ensina nada. (policial civil in MINAYO \& SOUZA, 2003, p.106)

Verificar como se deu a formação policial, no caso do Programa Delegacia Legal, e pesquisar as origens dessas resistências encontradas, seria uma importante reflexão. Essa verificação nos leva à outra causa da resistência que apontamos e refere-se especificamente aos cursos de formação continuada, realizados via web. Sua importância para nossa análise deve-se ao fato de tais cursos constituírem o centro da política de formação continuada de todos os policiais lotados em delegacias legais. Esse modelo de curso mantém-se até a atualidade e corresponde à contrapartida necessária para a obtenção da bolsa-formação.

Seu formato é semelhante àquelas apresentações de slides onde a cada clique se avança uma tela. O aluno é orientado a percorrer todas as telas do curso e ao final tem sua leitura aferida por uma série de questões. Tecnicamente, os cursos cumprem as orientações gerais para elaboração de materiais de Educação à Distância: apresentam seus objetivos gerais no início de cada curso, apresentam os objetivos específicos no início de cada módulo, revisam os conteúdos ao fim de cada módulo, explicitam os conhecimentos e competências que os alunos deveriam dominar ao final do curso. Não foi um problema técnico que levou o Programa a enganos na elaboração dos seus materiais pedagógicos.

O conteúdo dos cursos limitava-se a apresentar saberes jurídicos numa espécie de resumo de lições de Direito Penal. Discutiu-se em numerosos módulos os artigos do Código Penal, seus incisos, os agravantes e atenuantes de cada crime e pautou-se por disseminar conhecimentos e 
saberes próprios do mundo jurídico. Esse raciocínio traz subjacente uma hipótese que iguala o saber forense e o saber policial. Dito de outra forma, investigação e direito seriam, senão sinônimos, gêneros de uma mesma espécie. Se forem de fato gêneros de uma mesma espécie é salutar perceber uma acentuada distinção no próprio texto legal. Enquanto o processo judicial e seus trâmites são descritos em mais de 800 artigos do Código de Processo Penal, o inquérito policial - peça chave no oferecimento da denúncia do Ministério Público e no desenrolar de toda ação do sistema de justiça criminal - é exposto e definido em apenas 19 artigos do mesmo Código. Se ao teorizarmos o trabalho da polícia nos pautarmos somente pelos textos legais temos que reconhecer que a teoria, de fato, é muito rasa. Opera-se na prática a fantasia jurídica que separa o procedimento policial de todo o resto do processo judicial.

Acrescente-se a isso, o fato dos cursos de capacitação profissional utilizarem personagens que dialogavam entre si - técnica comum na elaboração desse tipo de material. Contudo, essa tentativa de "diálogo" com personagens caricaturais e falas em balõezinhos, muito próximo das histórias em quadrinhos, acabou por fazer os policiais se sentirem menosprezados pelo formato quase infantil usado. Não é difícil supor como operadores do direito, que são os policiais, sentiram-se ao final de suas carreiras sendo "qualificados" através de resumos de processo penal apresentados em quadrinhos.

A tese da subcultura policial antipática à reflexão e ao debate parece se fortalecer quando constatamos o limitado avanço democrático - oriundo da Constituição de 88 - sobre as instituições policiais brasileiras: sua discricionariedade ainda parece se manter isenta do controle público e poucas são as alterações em seus métodos e práticas. Monet (2001), demonstra surpresa com a estranha similitude entre a conduta de policiais de variados países: mesmo com estruturas policiais bastante diferenciadas, o fato dos policiais ocuparem uma posição semelhante em diversas sociedades - natureza idêntica das funções, titulares dos mesmos poderes de pressão, o peso da hierarquia e o isolamento social - acabaria por dotá-los de um discurso que clama sempre por mais autonomia, não reconhece críticas externas e os orienta para uma posição política corporativista. A partir daí, o autor supõe ser também capaz de encontrar uma espécie de cultura policial que "se marca, finalmente, por um conservadorismo intelectual que, sob a capa do pragmatismo, privilegia o olhar rasteiro, a tomada em consideração apenas dos elementos concretos e o anti-intelectualismo." (MONET, 2001 apud ROLIM, 2007, p.34) A teoria INTRATEXTOS, Rio de Janeiro, Número Especial 4(1): 53-72, 2013. ISSN 2176-6789 
aprendida na academia seria sempre um obstáculo a ser superado diante dos desafios do dia-a-dia, da prática.

\section{Limites e possibilidades da formação policial como instrumento de reforma}

Poncioni(2005) afirma que, apesar de presenciarmos inovações na área de formação profissional, poucas iniciativas foram capazes de conduzir a uma mudança efetiva nas práticas e procedimentos correntes inscritos em uma atuação predominantemente arbitrária e violenta. Segundo a autora, operamos ainda com uma perspectiva burocrático-militar, em que o policial é concebido como um

aplicador imparcial da lei, relacionando-se com os cidadãos profissionalmente, em condições neutras e distantes, cabendo-lhe cumprir os deveres oficiais, seguindo os procedimentos rotinizados, independentemente de inclinações pessoais e a despeito das necessidades do público não enquadradas pela lei. (PONCIONI, 2005, p.590)

Esse modelo de polícia profissional tradicional ao surgir, na virada do século XIX para o século XX, aparece como uma inovação que tentava trazer aos corpos policiais mais disciplina, menor discricionariedade e maior profissionalismo. O tipo ideal da atuação policial, nesse modelo, inicia-se quando requisitada e conclui-se restringida pela aplicação legal: a instituição policial espera por um crime para agir. Sua vocação para o controle do crime, como tarefa da competência policial, parece exigir uma tipificação do fato criminoso anterior à qualquer atuação. Essa obsessão, com a fixação dos "tipos penais" na formação policial, acaba por reforçar uma postura reativa dos funcionários: se sua atuação é pautada pelos tipos penais, não há de se falar em polícia antes do aparecimento do artigo penal: do "121", do "157", do "171". Se apenas damos resposta aos artigos do código penal, e não ao conflito, só agimos frente às ações tipificadas: sua ênfase no controle do crime, acontece em detrimento de outras tarefas, também exigidas constantemente dos policiais, mas cujo enquadramento legal não oferece respostas. Trata-se especificamente das questões de manutenção da ordem, negociação de tensões, composição de conflitos - tarefas centrais e demandadas a todo momento dos policiais mas para as quais os policiais não recebem nenhum treinamento específico. "Deste modo, a formação e o treinamento policial fornecido nas academias de polícia, quase sempre atados rigorosamente

4 Artigos do Código Penal referentes aos crimes de homicidio, roubo e estelionato.

INTRATEXTOS, Rio de Janeiro, Número Especial 4(1): 53-72, 2013. ISSN 2176-6789

Página 62 
aos aspectos normativo-legais do trabalho, acabam sendo simplistas e irreais, levando o indivíduo a descartar o que foi ensinado na academia nesta fase de socialização." (PONCIONI, 2005, p.592)

Se o objetivo do Programa é alterar as práticas e qualificar os policiais para o atendimento ao público, teríamos que contar com a mínima adesão deles. Não seria discutindo direito que a polícia converteria representações e criaria novas práticas adequadas a um exercício policial democrático.

\begin{abstract}
Geralmente, a formação é definida a partir do que a empresa ou outra instituição considera importante à sua política de organização e gestão do trabalho. (p.97) A capacitação oferecida por determinada organização a seus funcionários indica, pelo menos em tese, o tipo de conhecimento teórico-prático que será prioritariamente demandado para a execução de tarefas produtivas que se esperam desse indivíduo. $\mathrm{O}$ trabalhador, por sua vez, vê na capacitação a possibilidade de maior autonomia e reconhecimento. (p.98) Entretanto, a capacitação oferecida também revela o "perfil do profissional ideal" e o tipo de habilidades teóricas, tecnológicas e pessoais que se espera de um funcionário. (p.99) (MINAYO \& SOUZA, 2003)
\end{abstract}

Pesquisando a Polícia Civil do Rio de Janeiro, as autoras aplicaram quase 1.500 questionários em uma vasta pesquisa sobre condições de trabalho e saúde do trabalhador e encontraram dados importantes para a discussão que desenvolvemos aqui. Questionados sobre formação policial, apenas $43,6 \%$ dos policiais pesquisados afirmaram ter estudado técnicas de investigação; quando considerados apenas os policiais civis que trabalham em delegacias, essa proporção cai para 40,8\%. É preocupante o fato de cerca de $60 \%$ dos policiais terem afirmado não se recordar desse assunto em seu período de formação. Juntamente com esses números, outros ainda dão melhor idéia do tamanho do desafio que a Polícia Civil tem pela frente: apenas 40,5\% afirmaram ter estudado os direitos da criança e do adolescente, somente $36,7 \%$ discutiram o tema da violência de gênero e uma porcentagem ainda menor $(34,3 \%)$ mencionou ter debatido o relacionamento da polícia com os cidadãos. (MINAYO \& SOUZA, 2003)

É importante, contudo, salientar que não se trata de uma questão de currículos - como se o problema da polícia fosse uma ignorância dos códigos legais - mas sim de uma formação capaz de alterar qualitativamente a concepção dos policiais sobre qual é a função da polícia, como ela entende o resultado positivo de seu trabalho, quais os limites da sua atuação. Não basta incluir uma disciplina de direitos humanos em um programa teórico que avança em direção distinta. Os 
homens e mulheres que compõem o corpo policial trazem consigo representações e valores de uma sociedade profundamente ainda marcada por status e hierarquias que colidem frontalmente com uma ordem igualitária. É previsível que sejam portadores de equívocos e preconceitos; se as políticas públicas de formação não são capazes de revertê-los completamente, podem pelo menos se furtar de reforçá-los.

Minayo afirma seguir a sugestão de Bretas (1997) para que nosso foco de pesquisa não esteja atento apenas a uma perspectiva institucionalista, mas sim interessado pelos homens e suas atividades cotidianas na sua prática profissional:

É aí que se estruturam os significados que conformam a ação policial em grande parte independendo de estruturas organizacionais, tantas vezes reformadas sem alcançar resultados efetivos (...) é na atividade cotidiana dos policiais que podemos buscar as origens de seu saber, que ainda permanece largamente informal e distinto do treinamento que mais e mais se tenta oferecer nos centros de instrução (BRETAS, 1997 apud MINAYO, 2003, p.11)

Quando criticamos o formato inadequado dos módulos de formação, não pretendemos com isso menosprezar a necessidade dos materiais educativos discutirem com a representação dos policiais sobre vários temas, inclusive sua atividade. Essa negociação vai ser bem sucedida de acordo com nossa capacidade de diálogo e não pode estar iludida com a pretensão de reformar mecanicamente uma instituição com séculos de hábitos e rotinas sedimentados.

Conhecer a percepção que os policiais têm sobre o fato de seu trabalho ser ou não socialmente reconhecido é de fundamental importância para entendermos como eles se situam tanto em relação às atividades que realizam, quanto do ponto de vista da identificação. (...) Comecemos pelo que os próprios policiais consideram "ser policial" (MINAYO, 2003, p.164)

Nenhum corpo policial resume-se à pura instrumentalidade. Toda organização burocrática, seja ela qual for, adapta as regras prescritas ao cotidiano prático. Não se trata ainda de resistência, mas de entender qual o teor da ordem e implementá-la com os meios disponíveis. Há sempre um intervalo entre o prescrito e o observado: não há organização formal sem organização informal. Não se trata de um mero decalque, mas de uma necessária combinação. Conforme Monjardet (2002), a greve "branca" - a "operação padrão" - evidencia essa ambiguidade: se os controladores de vôo, em uma manifestação, cumprirem todas as regulações a eles direcionadas, 
o tráfego aéreo pára; se os fiscais da alfândega, protestando, observarem todos os códigos de revista, o porto pára também. Compreender tal hiato é o primeiro passo para a construção de um material de aperfeiçoamento que entenda a importância de englobar os profissionais de ponta, capilares, para as mudanças propostas. A questão não é formar novos policiais, mas sim remontar conceitos e reformular paradigmas já vigentes. É um equívoco acreditar que a violência policial é consequência de uma formação deficitária: as "balas perdidas" que matam e ferem tantas vítimas não são resultado da falta de treinamento sobre abordagem, tiro ou uso da força. Isso é o que pensam os policiais que insistem em reivindicar mais treinamento de tiro e técnicas de defesa pessoal. Que os policiais individualmente sejam levados a concluir que a única forma de aprimorar seu trabalho seja pelo melhor condicionamento do uso da arma de fogo não é estranho: deduzem apenas a competência que cotidianamente são chamados a assumir e a utilizar pelo senso comum.

Como adverte Lima,

O que estamos chamando de mau desempenho é realmente mau desempenho ou é desempenho segundo um modelo que, na raiz, legitima as ações que estamos questionando? Depois, é preciso saber se os policiais fazem aquilo que consideramos errado porque não sabem o que é correto ou se, sabendo-o, simplesmente deliberam fazer o contrário. Eventualmente, poderemos concluir que o que estamos considerando despreparo é, na verdade, um preparo informado por valores e ideologia diferentes daqueles que informam explicitamente o nosso julgamento. (2003, p.70)

Acreditando ser o Programa Delegacia Legal um importante passo em direção a uma polícia mais republicana, a indisposição dos policiais torna-se um entrave ao aperfeiçoamento dos profissionais que, em última instância, são os responsáveis pela implementação concreta de qualquer política definida na cúpula. Sociedades ibéricas como o Brasil, com códigos extensos e rígidos em quase todas as áreas da vida, acreditam ser inexistente esse desencontro entre a intenção do legislador e a ação do operador da lei. Encontrar um instrumento capaz de incorporar esse descompasso e conquistar os policiais para o importantíssimo debate sobre segurança pública, o papel da polícia investigativa e do policial diante dos conflitos, possibilita uma mudança qualitativa na formação policial, habilitando-a para uma disputa sobre valores e revisão de preconceitos e práticas equivocadas.

Quando os reformadores da polícia civil optam por centrar sua política de formação na replicação de saberes jurídicos, acabam por reforçar uma postura reativa e incrementam o 
sentimento de desprezo por atividades que não estejam sob o ditame da sanção legal. Tarefas próprias da manutenção da ordem, como organizar uma fila em um estádio, intervir em um conflito familiar, ou ainda, atuar em situações onde o comportamento das pessoas não seja determinado pela lei, mas onde é exigido algum tipo de civilidade, também são tarefas do mandato policial. O desprezo por essas tarefas, que não estão circunscritas ao combate ao crime, gerou a concepção de garbage calls - citada por Poncioni (2005) e que, na versão da polícia carioca, foi denominada de "feijoada". Tratam-se de demandas à atuação policial que requerem competências mais próximas da conduta de assistentes sociais e conciliadores judiciais, com clara ênfase na negociação, composição e transação de divergências e conflitos. Abaixar o som de uma festa, negociar a via pública com uma manifestação, são todas tarefas policiais cuja qualificação requer uma lógica completamente distinta daquela em curso. Não são raras as vezes que presenciamos ações absolutamente violentas e desmedidas da polícia frente a problemas absolutamente solúveis. Essa demarcação sempre tensionou o debate sobre o limite das competências policiais, ora reivindicando essa dimensão social, ora reivindicando a dimensão repressiva. (BRETAS, 1997)

Atualmente, atravessamos uma política criminal que delega à polícia inúmeras atividades que extrapolam sua dimensão repressiva. São inúmeros os lugares onde os policiais estão sendo chamados a exercer seu ofício: grandes shows e eventos, escolas secundárias, campi universitários; não é difícil supor a potencialidade explosiva dessa política uma vez que não condiciona seus profissionais a uma atuação distinta e mais adequada às essas novas responsabilidades. Caminhar nesse sentido, desconstruindo alguns paradigmas e concepções, implica um processo lento e necessitará da participação de outros sujeitos nesse debate que não apenas os policiais. Todavia, um material que sirva de qualificação para policiais não pode deixar de explicitar tais polêmicas e trazê-las ao debate da categoria.

Minayo e Souza se espantam com uma espécie de paradoxo encontrado na aplicação dos questionários em sua pesquisa sobre a polícia civil. Mesmo entre o grupo dos que participam dos cursos de capacitação oferecidos pelo Programa Delegacia Legal,

apenas 20,4\% afirmam que sempre ou muitas vezes lhes é facultada a oportunidade de programas de reciclagem e de aperfeiçoamento profissional. (...) Como interpretar o

INTRATEXTOS, Rio de Janeiro, Número Especial 4(1): 53-72, 2013. ISSN 2176-6789 Página 66 
fato de a maioria, em algum momento, ter afirmado que tem poucas oportunidades de aprimoramento oferecidas pela Corporação e, em contrapartida, citarem que têm frequentado vários cursos? Em termos gerais, tais respostas podem estar indicando que as oportunidades são poucas e esporádicas, consideradas as necessidades. (grifo nosso, 2002, p.104)

Contudo, é possível uma interpretação diversa com os dados disponibilizados pelas autoras: quando apenas $20 \%$ dos policiais afirmam ter oportunidade de aperfeiçoamento profissional, ao contrário senso, $80 \%$ deles afirmam que os programas de reciclagem não constituem aprimoramento profissional. É possível haver descompasso entre o que os policiais consideram um treinamento adequado e o que poderíamos definir assim, contudo é impossível desconsiderar o fato de que $80 \%$ dos educandos não concordam com a política educacional em curso.

Monjardet (2002) ajuda-nos a pensar sobre essas questões quando aponta que, em alguma medida, a idéia que fazemos de uma formação policial adequada é influenciada pelo modo como compreendemos a competência policial. Ele apresenta esse dilema polarizado entre duas concepções: uma delas privilegia a experiência acumulada e os traços subjetivos do indivíduo; enquanto a outra prima pela definição de um conjunto de saberes técnicos capazes de dar objetividade e autonomia ao exercício policial.

A primeira concepção, de longe a mais difundida, compreende a competência profissional na polícia como um encontro entre traços de caráter - bom senso, iniciativa, sangue frio, julgamento - e um acúmulo de experiências que se expande com o passar do tempo. Para essa concepção, a competência fundamental (subjetiva) deveria ser identificada e desenvolvida com o passar do tempo (empírica). A ilustração é semelhante à formação de um motorista: "o motorista competente se destacará do conjunto dos detentores da carteira de habilitação pela adição, às qualidades iniciais de partida, de uma experiência cada vez mais extensa da direção." (MONJARDET, 2002, p.124) A obtenção da carteira, portanto, não seria bastante para garantir as qualidades do motorista. Essa concepção de competência privilegia um conjunto de características pessoais, que definirá o ingresso do policial à instituição, e relegará à empiria o método acertado para o desenvolvimento da competência profissional. O que se adquire são receitas, construídas pelo erro ou acerto, e que são transmitidas pelos companheiros: os detentores dessa arte recusam repetidamente a sistematização de suas rotinas, visto que suas 
atividades não são exatamente técnicas, mas uma expertise.

Não é na escola que se aprende: eu sou totalmente categórico, é preciso aprender no trabalho, em situação real, onde cada caso é diferente [...] um cara que tem cinco ou seis anos de experiência é competente, viu-se de tudo (Guarda, Paris)

Cinco meses de escola no CAPU (denominação das escolas de polícia na França) e não aprendi nada, mas nada mesmo, apenas teoria e lavagem cerebral [...] comecei a aprender no estágio no subúrbio, acompanhado pelo cabo [...] aprendi com os colegas, com sua ajuda, ligando-me a eles (Guarda, subúrbio)

O que conta é a experiência do ofício, mas também o comportamento de cada um: há os que logo partem para ignorância, eu reflito antes (Guarda, subúrbio)

Não há procedimentos precisos, é por avaliação, nada programado, sempre imprevisto, é aí que está o interesse do trabalho. Procedimentos, não é possível, nada é programável (Cabo, subúrbio) (MONJARDET, 2002, p.124)

A segunda concepção polariza radicalmente com a anterior e identifica a competência profissional fundamentada sobre um conjunto de conhecimentos formais cujo domínio mitigariam as diferenças da experiência entre "jovens" e "antigos", minimizariam a importância das idiossincrasias e ampliariam a autonomia do policial. Sua descrição do ofício policial é exatamente o contrário da primeira hipótese: não se trata de partir das experiências individualizadas, mas de um corpus teórico definido de maneira geral para, a partir dele, adaptarse às ocorrências pontuais. A generalidade não implicava seu desuso, pelo contrário, essa aplicação sempre necessária dotava de autonomia o agente policial que agisse dentro das regras: conhecendo-se profundamente essas regras objetivas e esquivando-se das condutas interditadas, a ação policial não seria questionada de ilegal ou arbitrária. "Os elementos que constituem a competência na acepção precedente são apenas paliativos - substitutos artesanais, inúteis e mesmo nocivos - de uma real qualificação profissional; e o discurso sobre o campo, a experiência, o tempo de serviço etc. é apenas racionalização de uma ignorância fundamental" (MONJARDET, 2002, p.126)

A fala de um Guarda de Província francês é expressiva - depois do serviço militar, emprega-se por pouco tempo como metalúrgico, para depois entrar para polícia com 20 anos de idade, em busca de uma "qualificação" e da possibilidade de "progressão hierárquica" na carreira. Passados três anos desde seu ingresso, aguarda sua promoção para o grau de cabo: 
É inimaginável a falta de conhecimentos profissionais das pessoas daqui: em minha brigada, dois terços dos rapazes não sabem datilografar um processo de infração de trânsito [...] De minha parte, conduzo meus processos até o fim, faço as audiências eu mesmo, sem repassar o dossiê à brigada. O ponto fraco aqui? É primeiro e antes de mais nada a falta de conhecimentos profissionais em todos os níveis [...] depois, o segundo ponto fraco é a ausência de autonomia devido à canga administrativa e à falta de extensão de nosso poderes. (Guarda de subúrbio in MONJARDET, 2002, p.126)

Em contradição com o "artista" que é longa e progressivamente apresentado a "receitas" confeccionadas pelos seus "companheiros", nessa segunda concepção o policial é um "diplomado" que domina competências e saberes rigorosos, precisos e objetivos que the permitem maior autonomia sobre seu trabalho. De acordo com essa segunda concepção, digamos teórico-objetiva, a juventude de um oficial não é desrespeitosa, desde que ele tenha sido "qualificado" para o exercício do cargo. Entre os defensores dessa corrente, o critério de "dupla entrada" para a ocupação de cargos de chefia e cargos de execução, separadamente, também não é em si um problema; assim como também não são resistentes à direção "civil", por quadros externos da instituição.

Comparando as duas concepções sobre competência policial, vemos que elas refletem duas dimensões em si do trabalho policial. A inspiração subjetivo-empírica vincula-se a práticas conciliadoras onde a "arte" da negociação exige de fato competências muito distintas da "aplicação da lei", do law enforcement; já a inspiração objetivo-teórica inclina-se à atividades repressoras, onde a legalidade exigida requer o cumprimento de formalidades que devem ser dominadas pelo agente policial. Dito de outra forma, para conseguir deter um adicto violento, e levá-lo até o hospital apenas, é preciso muito mais negociação e "arte" do que, comparativamente, exige-se quando se detecta que um indivíduo tem uma ordem de prisão contra ele. No primeiro caso, se o indivíduo se acalma, é possível até mesmo desistir da ação policial; no segundo caso, essa opção não existe. Quando não cabe ao agente policial nenhum tipo de negociação, quando sua ação é estritamente descrita nos códigos legais é que, contraditoriamente, o policial sente sua discricionariedade aumentada: cumpridas as formalidades legais, não há o que se falar da legalidade da ação policial, nem tampouco questionar a autonomia da sua decisão, coisa que poderia ser questionada no primeiro caso. 
Não se trata de escolher entre uma das duas competências visto que toda atividade policial implica, em alguma medida, ambas as dimensões. Instaurar o debate sobre competências com os policiais pode ser um importante passo para alterarmos suas representações sobre o que significa "ser policial". Novamente, não se trata de formar "novos" policiais, mas de conseguir difundir representações nativas capazes de reverter equívocos mútuos de ambas as correntes.

Cunha (2004) nos alerta ainda para o fato de que a iniciação de um profissional é um processo sempre mais amplo que a simples aquisição de conhecimentos específicos para "iniciados". Trata-se mesmo de um rito de passagem, com sua liminaridade característica, e a necessária busca da nova identidade. Nesse processo, os antigos e os novos disputam não só entre tarefas e responsabilidades a serem cumpridas, mas também por status e posições dentro da instituição. O processo de socialização profissional não pode ser entendido apenas como o processo de aquisição de técnicas objetivas.

Dessa forma, o modo particular como o agente policial enxerga o "mundo ao seu redor", adquirido ao longo de seu processo de socialização e formação profissional, e, consequentemente, o modo através do qual ele desempenha seu papel, é uma chave fundamental para a compreensão do comportamento e das atitudes da polícia. (CUNHA, 2004, p.203)

\section{Considerações finais}

Se o Programa Delegacia Legal deseja reverter a desconfiança da população frente à polícia e reforçar as atividades investigativas da polícia judiciária não pode perder de vista a ferramenta ímpar de que dispõe: a manutenção do projeto de formação permanente. Se é verdade que ele pode ter sido capturado para alcançar outros objetivos da Administração - como conter a insatisfação salarial - sua permanência, pelo contrário, acabou por instaurar novos hábitos e hoje a resistência ao curso, em si, diminuiu bastante. Todavia, deveria se esquivar de reforçar modelos já conhecidamente ineficazes para o estabelecimento de uma compreensão mais democrática da missão policial. Incorporar outras habilidades, além das meramente repressivas, implica numa reinterpretação sobre o mandato policial. Para essa tarefa, o projeto de formação permanente pode se constituir em um singular espaço de debates e reflexão dentro da polícia, desde que para 
isso, englobe os policiais responsáveis pela implementação das mudanças e os tornem também agentes da transformação institucional. Sem isso, sabemos que todos os mecanismos de resistência burocrática são empregados e os êxitos das reformas são, quando não inviabilizados, retorcidos para atender aos interesses dos agentes da transformação.

A reclamação dos policiais contra os cursos que eles acreditam ser demasiadamente teóricos não representa uma resistência aos objetivos centrais do Programa, nem tão pouco uma postura anti-intelectual, como queria Monet. Sua principal identidade é com a prática investigativa à qual atribuem sua competência específica e pela qual lutam: muitos protestam ainda hoje por fazerem parte de uma "polícia de papel" - cuja ocupação central seria, muito mais, voltada às atividades burocráticas e repetitivas que à prática investigativa. O protesto dos policiais está muito mais vinculado à percepção da inadequação daquele material, que com uma antipatia pela atividade educacional. Buscar um material pedagógico que consiga dialogar sobre a prática policial, levando os policiais a refletirem sobre o que eles consideram como sendo o ofício policial, já contribuiria, no mínimo, para identificar a dimensão da polêmica e o tamanho dos desafios que deverão ser enfrentados na reforma da polícia.

\section{Referências Bibliográficas}

BRETAS, Marcos Luiz. Ordem na cidade: o exercício cotidiano da autoridade policial no Rio de Janeiro, 1907-1930. Rio de Janeiro: Ed Rocco, 1997

CUNHA, Neiva Vieira. "Como se "fabrica" um policial: algumas considerações em torno dos processos de socialização e formação profissional”. Revista Comum. n²2, p. 198 - 207, 2004

CLIFFORD, James. "Sobre a autoridade etnográfica.” In: Gonçalves, J. R. S. (org) A experiência etnográfica: antropologia e literatura no século XX. Rio de Janeiro: EdUFRJ, p. 17 - 58, 2002

LIMA, Roberto Kant. "Direitos Civis, Estado de Direito e "Cultura Policial": A Formação Policial em questão”. Revista Preleção. n01, p. 67 - 80, 2007

MIRANDA, Ana Paula et al. "Antropologia e Políticas Públicas: Notas sobre a avaliação do trabalho policial". Cuadernos de antropología social, $n^{\circ} 25,2006$

MINAYO, Maria Cecília; SOUZA, Edinilsa Ramos (org). Missão Investigar: Entre o ideal e a realidade de ser policial. Rio de Janeiro: Ed Garamond, 2003

MONJARDET, Dominique. O que Faz a Polícia: Sociologia da Força Pública. São Paulo: 


\title{
EdUSP, 2002
}

PONCIONI, Paula. "O modelo profissional e a formação profissional do futuro policial nas academias de polícia do Rio de Janeiro”. Revista Sociedade e Estado, v.20, n³, set/dez 2005

ROLIM, Marcos. "Caminhos para a inovação em segurança pública no Brasil”". RevistaBrasileira de Segurança Pública. v.01, p.32 - 47, 2007

\section{REFORM OF POLICE AND POLICE TRAINING ON DELEGACIA LEGAL PROGRAM.}

\begin{abstract}
This article is a brief description of Delegacia Legal Programme, implemented by the Polícia Civil do Estado do Rio de Janeiro, since 1999. The project has brought great changes in the routines and structure of police stations on order to modify the relationship between police and society and enhance the investigative capacity of the judiciary police. A hallmark of the program was the investment in ongoing training of the police officers who have to attend refresh courses monthly. We argue that the strength of police against the courses proposed linked more to the inadequacy of the format and content of educational initiatives that an pragmatic position. Despite the intentions of reform, the courses reinforcing a repressive perspective of police action leaving reinforce other skills of the police mandate required for policing in a democratic state.
\end{abstract}

KEYWORDS: Programme "Delegacia Legal”, police training, policies public. 